\title{
Two dimensional modelling of flood flows and suspended sediment transport: the case of the Brenta River, Veneto (Italy)
}

\author{
P. Martini, L. Carniello, and C. Avanzi \\ Dipartimento Ingegneria Idraulica, Marittima, Ambientale e Geotecnica, Università di Padova, Via Loredan 20, 35131 \\ Padova, Italy
}

Received: 1 November 2003 - Revised: 3 February 2004 - Accepted: 3 March 2004 - Published: 9 March 2004

Part of Special Issue "Landslide and flood hazards assessment"

\begin{abstract}
The paper presents a numerical model for the simulation of flood waves and suspended sediment transport in a lowland river basin of North Eastern Italy. The two dimensional depth integrated momentum and continuity equations are modified to take into account the bottom irregularities that strongly affect the hydrodynamics in partially dry areas, as for example, in the first stages of an inundation process or in tidal flow. The set of equations are solved with a standard Galerkin finite element method using a semi-implicit numerical scheme where the effects of both the small channel network and the regulation devices on the flood wave propagation are accounted for.

Transport of suspended sediment and bed evolution are coupled with the hydrodynamics using an appropriate form of the advection-dispersion equation and Exner's equation.

Applications to a case study are presented in which the effects of extreme flooding on the Brenta River (Italy) are examined. Urban and rural flood risk areas are identified and the effects of a alleviating action based on a diversion channel flowing into Venice Lagoon are simulated. The results show that this solution strongly reduces the flood risk in the downstream areas and can provide an important source of sediment for the Venice Lagoon. Finally, preliminary results of the sediment dispersion due to currents and waves in the Venice Lagoon are presented.
\end{abstract}

\section{Introduction}

The events which occurred due to sever rainfall in November 1966 showed that several urban and rural areas in North Eastern Italy are potentially vulnerable to flooding. The specific case of Brenta River (flowing from north to south between Padova and Venice) and its main tributary offer an interesting case study.

\section{Correspondence to: P. Martini}

(p.martini@altieri.org)
The area close to two major rivers (Brenta and Bacchiglione) has been studied and a 2D mesh has been created covering about $3000 \mathrm{~km}^{2}$. The $2 \mathrm{D}$ computational domain is merged with a 1D network to represent the role of both the small channels and the regulation devices like weirs, sluices, banks, water pumps, one-way valves, pipes, etc.

The use of a coupled 2D-1D scheme is necessary, because we want to describe the effects of small channels in the computational domain. These small channels play a very important role on the propagation of flood waves on dried areas and they can not be described with 2D elements unless an extremely refined mesh is generated.

Starting from a tested framework (D'Alpaos and Defina, 1993) developed for fixed bed analysis, the numerical scheme has been reformulated, allowing its application on geometries where the convective terms and the turbulence phenomena no longer play a negligible role.

As the fix bed analysis is not always sufficient in engineering problems, the hydrodynamic model has been coupled with a morphological module to take into account the sediment transport phenomena and the bottom evolution of the computational domain.

It is clear that such a numerical model can be very useful to plan the safeguards necessary to reduce flood risk, taking into account the complexity of both the channel network and the boundary conditions.

In November 1966 the Brenta River was unable to convey the maximum discharges and consequently wide urban and rural areas were flooded. Not many mitigating works have been done after that event and therefore critical areas are still present, especially in the downstream part of the catchment. A few years ago river authorities started planning the construction of a hydropower reservoir in the mountain basin which would provide flood capacity: the design activities have not been concluded yet so the present topic has still a practical significance.

The model has been applied to analyse a flood similar to the one that occurred in 1966 over the areas close to the 
Brenta River, taking into account that urbanization has certainly increased the vulnerability of such areas.

It is thought, as previous studies have already demonstrated (Carniello, 2000), that if an event like the one in 1966 occurred now, it would generate an extremely dangerous flood.

In this paper we describe a possible solution, suggested to us by L. D'Alpaos and preliminarily investigated in the above work, that is able to significantly reduce the risk of inundation without major readjustments of bank top. We also verify the efficacy of this solution with respect to the local environment.

The proposed solution is based on the diversion of part of the flood discharges into the Venice Lagoon that is very close to the river course.

It is worth remembering that the Brenta River used to flow into the central lagoon before the diversion works performed by the Venetians. In the beginning of the XVI th century, mainly due to the filling of lagoon channels but also of the necessity to drain the border countryside (wet areas turned to agricultural land), the Venetians diverted the Brenta river from Dolo to the south into a new river (Scolo Brentella), reaching the ancient outlet of the Bacchiglione River that flowed in the southern lagoon behind Chioggia.

In the middle of the XVI th century, the Venice lagoon was definitely bereaved of both rivers but the increase in the river length caused by the two interventions noticeably increased the frequency of the flooding events, especially downstream of Dolo. Furthermore, the situation became worse as the minor slope caused deposition of sediments in the low course, reducing the conveying capacity of the river.

In the XVIII th century, famous hydraulic scientists proposed many interventions that were all declared to be able to guarantee the hydraulic safety in the low course. The present situation was designed and built in the XIX th century, under the Austrian Empire, by two famous hydraulic scientists, V. Fossombroni and P. Paleocapa. In Fig. 1, an 1847 map shows the historical situation in the river network and the interventions proposed by the two scientists on Brenta and Bacchiglione rivers. The main interventions on the Brenta River need to be mentioned:

- two lateral banks from Limena to Strà were designed to reduce the river length and to stop the natural migration of the river;

- the low course from Strà to Corte was straitened to reduce the river length;

- the diversion of Brenta in the Venice Lagoon behind Chioggia was designed 1) for the safeguard of the countryside from floods, not hiding the timely filling effects on the Chioggia Lagoon, and 2) to allow the navigation at Brondolo inlet.

From 1840 to 1867 , when the Brenta discharged into the Chioggia Lagoon, an average inflow of $1 \cdot 10^{6} \mathrm{~m}^{3}$ of sediments per year was estimated, these value being character- istic of the transport capacity during floods (Autorità di Bacino, 1997). After 1882, wide areas in the southern lagoon (the same areas where Brenta flowed into) were drained and devoted to agriculture, while Brenta River kept out of the lagoon towards Brondolo.

The interventions reduced the length of the river by approximately $30 \mathrm{~km}$ and, as a consequence, promoted the deepening of the bottom. Nonetheless, the interventions didn't prevent the countryside from being flooded during the catastrophic event of 1882 (Miliani, 1939) and in the event of 1966 (Tonini, 1968).

In this context, noticing that the actual situation of the Venice Lagoon is completely different from the one in the past that forced the Venetians to divert the Brenta from the lagoon, a new timely diversion of the Brenta River into the Venice Lagoon, not necessarily activated only during floods, appears reasonable and deserves careful evaluation.

Unfortunately, the old connection Strà-Venice Lagoon (Fig. 1, greatly reduced in width) cannot be re-activated as many small towns are now located along it and there are no banks on its sides.

The only solution available is the diversion into the waterway connecting Padova to the Venice Lagoon (PD-VE), the construction of which was interrupted in the 1980s when its commercial viability was doubted. All the studies performed in the following years on the opportunity to complete that waterway, for instance the one proposed by Thetis-InterPave (Thetis-InterPave, 1999), never considered two other possible uses (and its economic benefits) that would be complementary to the commercial one: the capacity of conveying discharges and sediments during flood events. Considering particularly the waterway PD-VE also as a driver of sediments, the advantage of its completion could be greatly improved.

From a methodological point of view we analysed all the effects of these new uses of the waterway showing not only the beneficial effects of reducing the hydraulic risk but also performing preliminary estimation on the impact in the Venice Lagoon.

The next sections follow this outline: firstly, the hydrodynamic and morphological models are briefly described relying to specific references for more details (Martini et al., 2003); then the hydraulic problems of the Brenta River concerning the flooding hazard are considered, showing the beneficial effects of the proposed solution. Finally, we show the preliminary results of the effect of this new sediment input in the Venice lagoon.

\section{2D-1D hydrodynamic module}

The hydrodynamic module solves the Saint-Venant equations derived from a form suitable for dealing with dry and wet areas (Defina, 2000). The standard 2D equations, averaged over the wet phase of the reference area $\left(^{-}\right)$, are written as:

$\frac{d\left(\overline{U_{x}}\right)}{d t}-\frac{1}{\rho}\left(\frac{\partial \overline{\tau_{x x}}}{\partial x}+\frac{\partial \overline{\tau_{x y}}}{\partial y}\right)+\frac{\tau_{b x}}{\rho Y}-\frac{\tau_{s x}}{\rho Y}+g \frac{\partial h}{\partial x}=0$ 


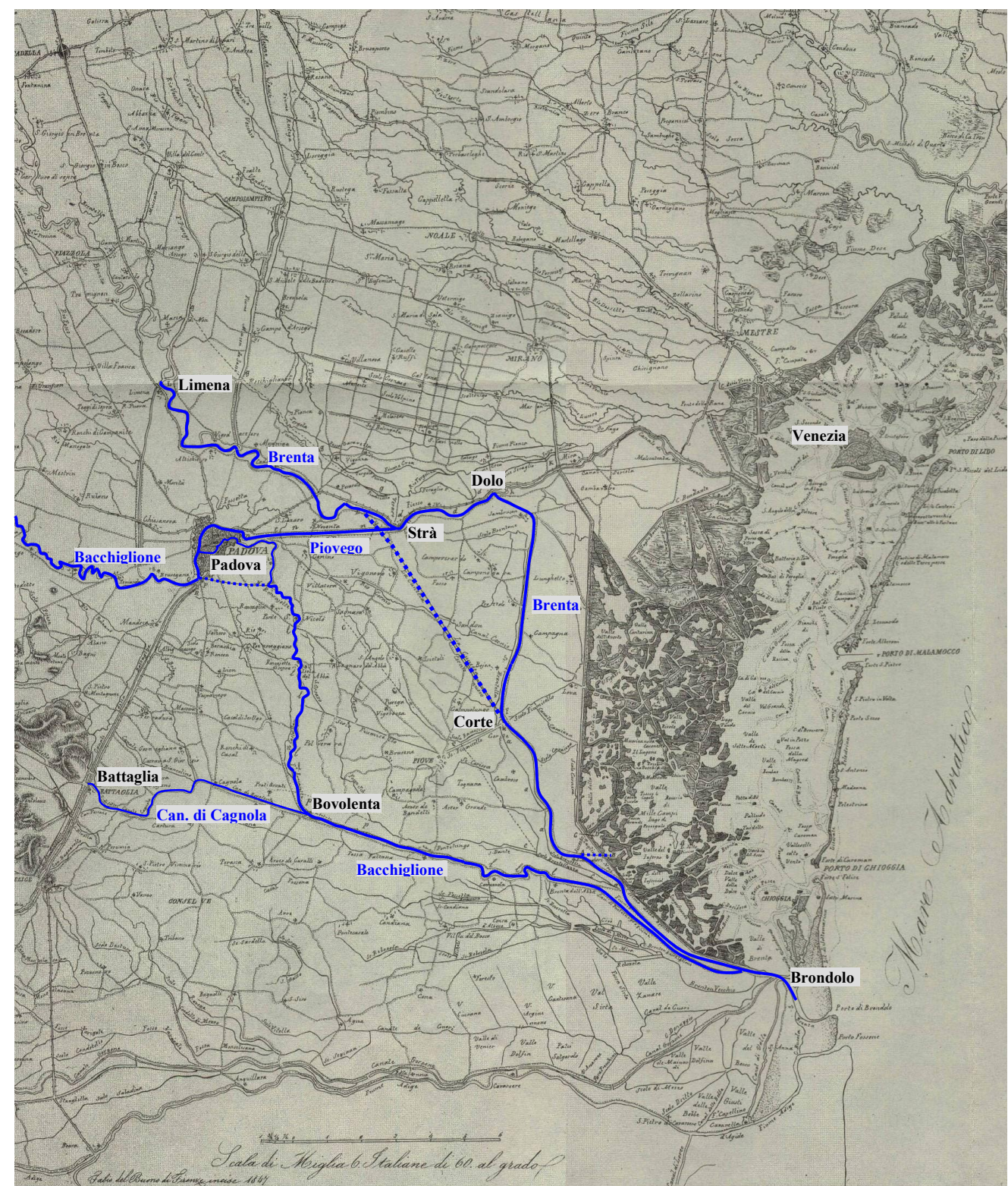

Fig. 1. River network between Padua and the Venice Lagoon from a 1847 map. (Pietro Casetta, 2002). Solid lines indicate the situation at the beginning of the XIXth century while dotted lines indicate the interventions performed by the P. Paleocapa and V. Fossombroni to reduce the length of Brenta and Bacchiglione.

$$
\begin{aligned}
& \frac{d\left(\overline{U_{y}}\right)}{d t}-\frac{1}{\rho}\left(\frac{\partial \overline{\tau_{y x}}}{\partial x}+\frac{\partial \overline{\tau_{y y}}}{\partial y}\right)+\frac{\tau_{b y}}{\rho Y}-\frac{\tau_{s y}}{\rho Y}+g \frac{\partial h}{\partial y}=0 \\
& \eta \frac{\partial h}{\partial t}+\frac{\partial\left(\overline{U_{x}} Y\right)}{\partial x}+\frac{\partial\left(\overline{U_{y}} Y\right)}{\partial y}=0
\end{aligned}
$$

where $\left(\overline{U_{x}}, \overline{U_{y}}\right)$ is the depth averaged velocity, $\mathrm{h}$ is the water elevation, $\eta$ is a h-dependent storage coefficient accounting for the actual area that can be wetted or dried during the flow, $\mathrm{Y}$ is the effective water depth, $\left(\overline{\tau_{x x}}, \overline{\tau_{y y}}, \overline{\tau_{x y}}\right)$ are the components of the turbulent stress evaluated by the Smagorinski scheme, $\left(\tau_{s x}, \tau_{s y}\right)$ are the components of the wind stress at the free surface and $\left(\tau_{b x}, \tau_{b y}\right)$ are the friction stresses at the bottom of the water column.
The $2 \mathrm{D}$ shallow water equations are solved on a triangular mesh. The momentum equations are discretized in time assuming the velocity as constant on the triangle. Velocity is then substituted in the continuity equation, which is solved in the water level (Casulli, 1990). The continuity equation is then discretized in space using a triangular mesh and a finite element formulation based on a linear approximation of the water level:

$h(x, y . t)+\sum_{n=1}^{N} h_{n}(t) \cdot \xi_{n}(x, y)$,

where $h_{n}(t)=h\left(x_{n}, y_{n}\right)$ is the water elevation at node $n$ and $\xi_{n}(x, y)$ is the linear base function. 

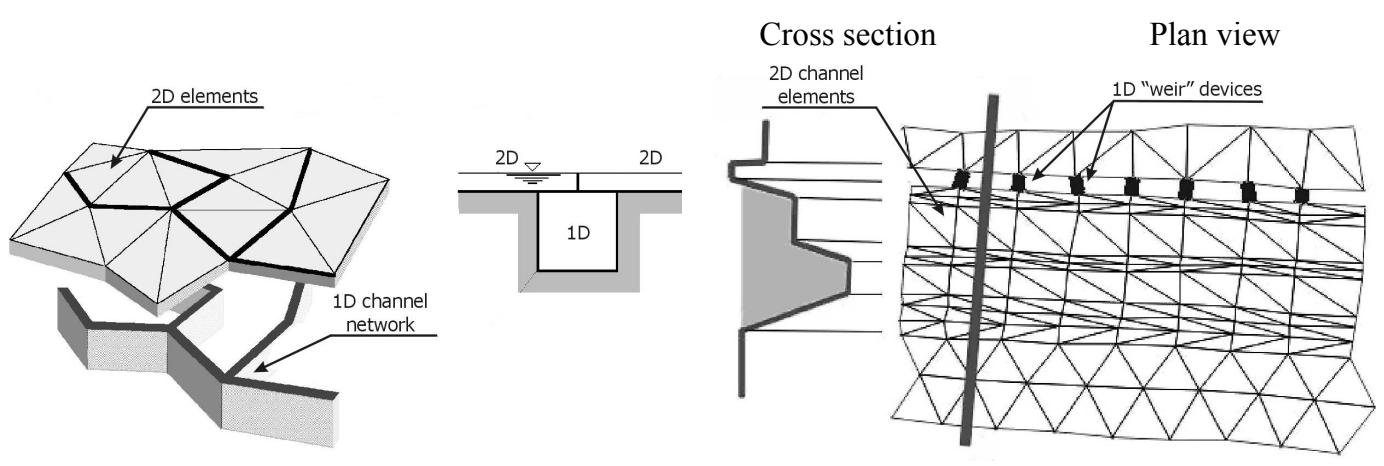

Fig. 2. Schematic representation of the coupling of a 2D domain with a $1 \mathrm{D}$ channel network (on the left) and the coupling of 1D weir devices with a $2 \mathrm{D}$ domain (on the right).

Applying the Galerkin method and recalling the first Green identity (Gambolati, 1994), the 2D final algebraic system can be expressed as: $\mathbf{A} \cdot \boldsymbol{h}=\boldsymbol{b}+\boldsymbol{Q}$ where the vector $\{\boldsymbol{Q}\}$ takes into account flux exiting from the 2D domain (towards the 1D network or due Neumann boundary conditions) or entering in the 2D domain (form the 1D network or due Neumann boundary conditions). In a similar manner, the algebraic system corresponding to the $1 \mathrm{D}$ channel network is set up as $\mathbf{A}^{\prime} \cdot \boldsymbol{h}=\boldsymbol{b}^{\prime}+\boldsymbol{Q}^{\prime}$. The complete matrices are assembled together and merged in a very simple way remembering that volume conservation at a shared node requires $\boldsymbol{Q}+\boldsymbol{Q}^{\prime}$ is null everywhere except where a Neumann boundary condition is superimposed. This coupling technique is described in detail in other papers (D'Alpaos and Defina, 1993; D'Alpaos and Defina, 1995).

Modelling of a river network, especially during floods, requires a realistic description of sections and devices placed along the course (gates, gaps, jumps, bars, weirs, sluices, etc. ...) as the specific hydraulic conditions (upstream and downstream the device) are very different from the ones modelled by the classical Saint Venant equations: for example, it is not possible to represent explicitly the jump on a bar or the flow in front of a sluice gate, but we can introduce their effects in the channel model.

In this way we have modelled many hydraulic devices in a 1D context, defining linearized relationship in the form of:

$$
Q^{\prime \prime}=k_{\text {upstream }} \cdot h_{\text {upstream }}+k_{\text {downstream }} \cdot h_{\text {downstream }}+k
$$

For example, the overflowing of the river banks is schematised in this way, where the coefficients depends on the shape of the crest, the bank elevation and the hydraulic conditions over the banks.

In a free flux condition where the overflowing discharge is modelled by a formula derived for a weir: $Q=C_{q} \cdot B \cdot \sqrt{2 g\left(h_{\text {upstream }}-h_{\text {bank }}\right)} \cdot\left(h_{\text {upstream }}-h_{\text {bank }}\right)$, the coefficients in Eq. 5 take the form of:

$$
\begin{aligned}
& k_{\text {upstream }}=C_{q} \cdot B \cdot \sqrt{2 g\left(h_{\text {upstream }}^{\prime}-h_{\text {bank }}\right)} \\
& k_{\text {downstream }}=0 \quad k=-C_{q} \cdot B \cdot h_{\text {bank }} \sqrt{2 g\left(h_{\text {upstream }}^{\prime}-h_{\text {bank }}\right)} .
\end{aligned}
$$

The superscript symbol refers to values at the previous time step, B is the length of the weir and $\mathrm{C}_{q}$ is a discharge coefficient. When both the hydraulic heads drive the flow, the energy balance gives the following simple expression $Q=B \cdot\left(h_{\text {upstream }}-h_{\text {bank }}\right) \cdot \sqrt{2 g\left(h_{\text {upstream }}-h_{\text {downstream }}\right)}$, under the hypothesis that 1) the energy of the current in the upstream and downstream position can be approximated with the hydraulic head $h$ and that 2) the kinetic energy on the bank crest is totally dissipated. In this situation, the coefficients in Eq. 5 take the form of:

$$
\begin{aligned}
& k_{\text {upstream }}=\frac{B \cdot \sqrt{2 g}\left(h_{\text {upstream }}^{\prime}-h_{\text {bank }}\right)}{\sqrt{\left(h_{\text {upstream }}^{\prime}-h_{\text {downstream }}^{\prime}\right)}} \\
& k_{\text {downstream }}=\frac{B \cdot \sqrt{2 g}\left(h_{\text {upstream }}^{\prime}-h_{\text {bank }}\right)}{\sqrt{\left(h_{\text {upstream }}^{\prime}-h_{\text {downstream }}^{\prime}\right)}} \quad k=0
\end{aligned}
$$

The complete 1D hydraulic devices are written in a matrix form leading to the algebraic system similar to the previous ones:

$$
\mathbf{A}^{\prime \prime} \cdot \boldsymbol{h}=\boldsymbol{b}^{\prime \prime}+Q^{\prime \prime} \text {. }
$$

As the 1D-device separates two 2D-1D channel domains, its functioning can always be represented as a positive and negative discharge source, the first being in one 2D-1D domain, the latter in the opposite 2D-1D domain.

The coupling method follows the technique proposed for Venice lagoon hydrodynamic (D'Alpaos and Defina, 1993; D'Alpaos and Defina, 1995) but it has two new important features: 1) the representation of non linear terms by a Lagrangian method based on "alignment" and 2) a turbulence closure based on Smagorinski's eddy viscosity (Martini et al, 2003). A schematic of the coupling is shown in Fig. 2.

\section{2D sediment transport module}

The model takes into account sediment transport both as bed load and as suspended load.

Bed load transport $\boldsymbol{q}_{b}$ is modelled on the Mayer-Peter and Muller formula (Lanzoni, 2000), where a modified critical 

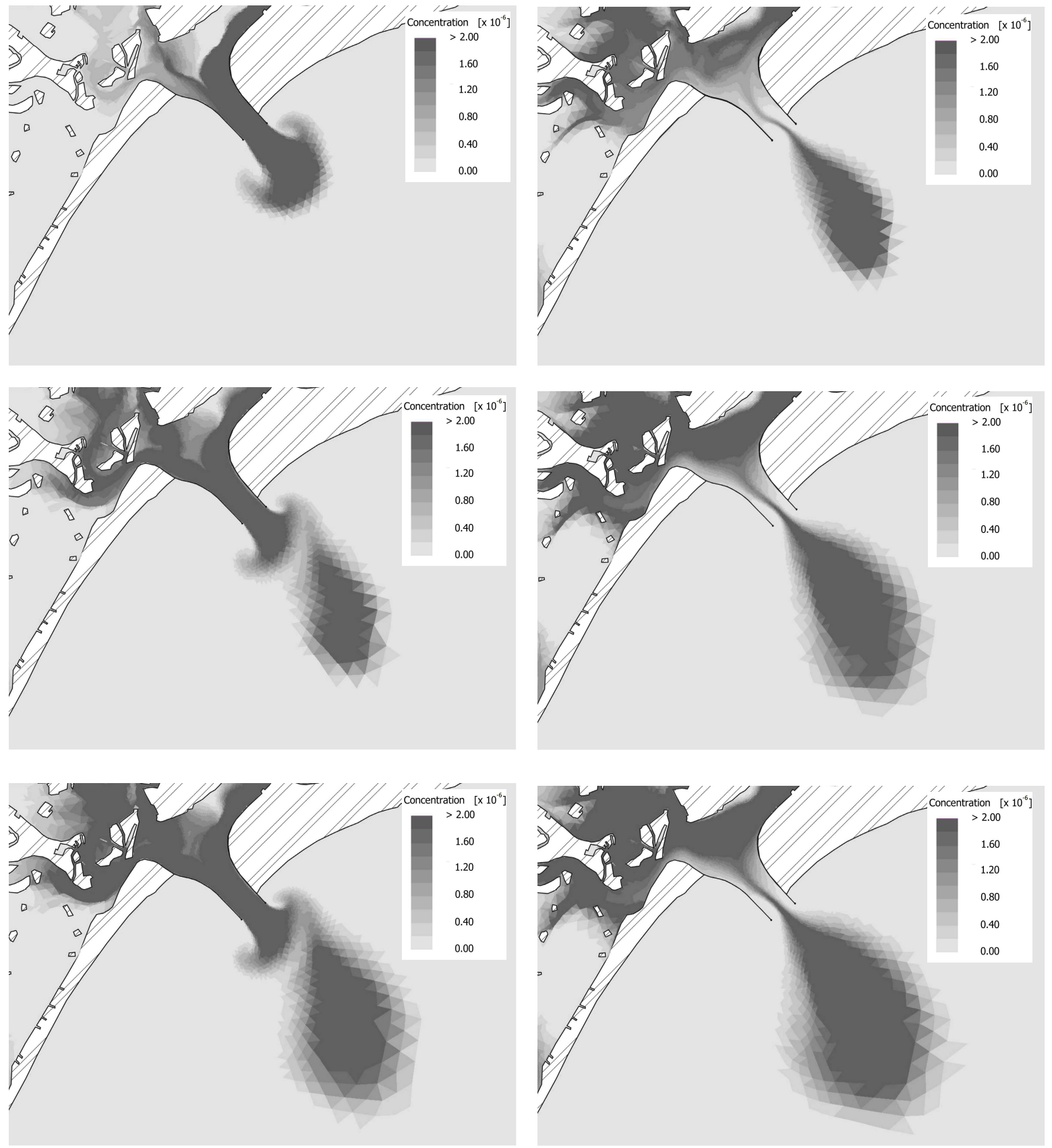

Fig. 3. Suspended sediment concentration at the Lido inlet in the Venice Lagoon during three tidal periods. Actual situation ( $\mathrm{t}=11 \mathrm{~h}$, $\mathrm{t}=17 \mathrm{~h}$, $\mathrm{t}=23 \mathrm{~h}, \mathrm{t}=29 \mathrm{~h}, \mathrm{t}=35 \mathrm{~h}$ and $\mathrm{t}=41 \mathrm{~h}$ ) (Martini et al, 2003).

shear stress takes into account the bed slopes and a simple scheme leads to the effective direction of the bed load (Talmon, 1995). The dimensionless critical shear stress in a sloped bottom is approximated as:

$$
\begin{aligned}
& \theta_{c r}=\theta_{c r 0} k_{\text {long }} \cdot k_{\text {tras } \nu}= \\
& \theta_{c r 0} \frac{\sin (\phi+\beta)}{\sin \phi} \cdot\left[\cos \alpha \cdot\left[1-\left(\frac{\tan (\alpha)}{\tan (\varphi)}\right)^{2}\right]^{0.5}\right]
\end{aligned}
$$

where $\theta_{c r 0}$ is the Shields stress (on the horizontal bottom), $\varphi$ is the angle of repose, $\alpha$ is the transverse slope and $\beta$ is the longitudinal slope.

The suspended sediment dynamic is governed by a depth averaged convection-dispersion equation written as:

$$
\frac{\partial(\bar{C} Y)}{\partial t}+\nabla \cdot(\bar{C} \boldsymbol{q})-\nabla \cdot(Y \overline{\mathbf{D}} \nabla \bar{C})=S
$$

where $\mathbf{q}=\left(\mathrm{q}_{x}, \mathrm{q}_{y}\right)$ is the total flow rates for unit width, $\overline{\mathbf{D}}$ is the dispersion tensor, and the source term $\mathrm{S}$ takes into account particle resuspension or particle settlement. We assume an 


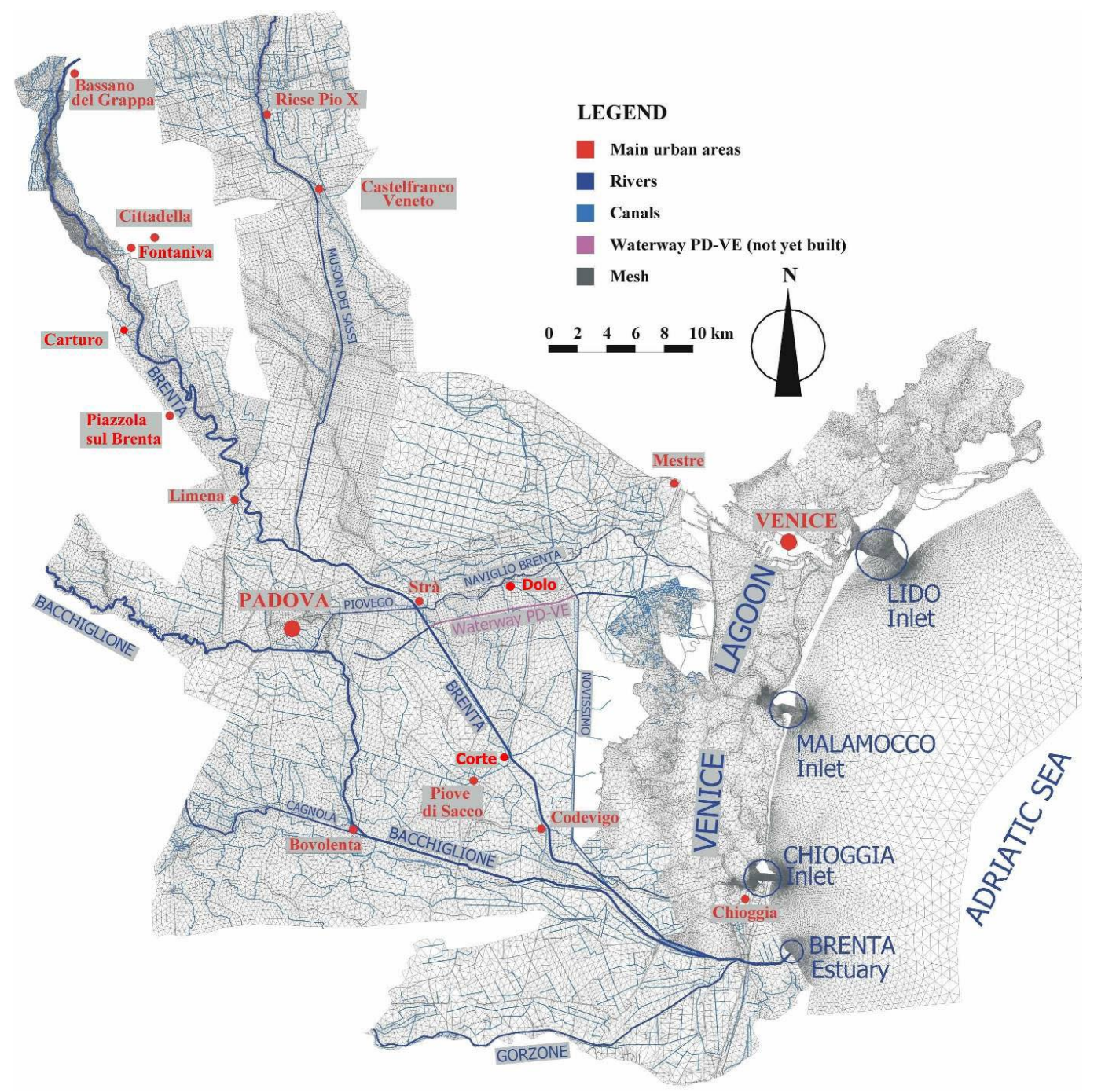

Fig. 4. 2D-1D domain utilized in the computations. The main channel network and the cities have been marked. Colour purple indicates the part of the waterway Padova-Venezia that needs to be completed.

entrainment function that considers the net sediment flux proportional to the difference between the value that the concentration would attain at equilibrium, $C_{e q}$ (Van Rijn, 1984b,c), and the actual local concentration, $\mathrm{C}_{b}$, the proportional constant being equal to the particle velocity normal to the bed, $W_{s}$.

The resulting form of the entrainment function is then

$$
S=W_{s}\left(C_{e q}-C_{b}\right)
$$

where the actual local concentration $\mathrm{C}_{b}$ at the bed bottom is evaluated assuming an instantaneous Rouse profile (Bijker, 1992; Van Rijn, 1984b, c).

Finally, the sediment transport module is linked to the hydrodynamics by the bed evolution equation:

$$
(1-n) \frac{\partial z_{b}}{\partial t}+\nabla \cdot \boldsymbol{q}_{b}=-W_{s}\left(C_{e q}-C_{b}\right)
$$

where $n$ is the soil porosity and $\mathrm{z}_{b}$ is the bottom elevation.
From a numerical point of view, both the suspended sediment equation and the bed evolution equation are solved following a finite volume formulation, as bed bottom elevation and concentration are properties defined as the mean values over the triangular elements.

\section{Venice Lagoon and Brenta River}

The actual boundary of the Venice Lagoon was fixed two hundred years ago and defines an area of about $550 \mathrm{~km}^{2}$ of which: $420 \mathrm{~km}^{2}$ are covered by water, $90 \mathrm{~km}^{2}$ by fish farms and $40 \mathrm{~km}^{2}$ by embankments, coastal barriers, islands and land. The lagoon is actually connected to the Adriatic Sea by three armoured inlets: Chioggia, Malamocco and Lido.

The actual morphodynamical situation of the lagoon is characterized by a loss of sediment. This is the result of the diversion of the rivers Brenta, Piave and Sile brought about by the "Serenissima Repubblica di Venezia" during the XVII 
century and of the construction of very large inlet jetties. These two factors have neglected the incoming of sediment both from the watershed and from the coastline via the sea. The historical evolution of the Venetian hydraulic problem requires more attention than reported here. The interested reader may find more details in a devoted monograph (Cessi, 1960).

Extended salt marshes areas disappeared during the last few centuries due to the lack of sediment input, to the increased energy of waves produced by wind and boat traffic, to the dredging of the industrial channel and to subsidence and eustatism. It has been estimated that the lagoon has a net loss of sediment of about $1000000 \mathrm{~m}^{3} /$ year and the final cause of this loss is the non-symmetric flow at the three armoured inlets, as it has been recently pointed out (D'Alpaos and Martini, 2003; Martini et al., 2003).

Figure 3, extracted from the last cited work, shows the contour plots of the suspended sediment concentration in a region close to the Lido inlet during three tidal periods $(T=12 h, h=-0.2 /+0.8)$. The size of the non-cohesive sediments has been considered equal to $\mathrm{d}_{50}=100 \mu \mathrm{m}$ and $\mathrm{d}_{90}=200 \mu \mathrm{m}$, while the relative density has been set equal to 2.0. The calculation clearly identifies a "breath" mechanism that day-by-day produces a continuous sediment loss.

At the same time several urban and rural areas in Veneto, between Padova and the Lagoon of Venice, are in danger of being flooded by the Brenta River. The possible consequences of a flood are probably similar to the ones that occurred in November 1966 during one of the most catastrophic events in Italian history.

During that event the Brenta River was unable to convey the maximum discharges, estimated in $2800 \mathrm{~m}^{3} / \mathrm{s}$ in Bassano at the closure of a $1500 \mathrm{~km}^{2}$ mountain basin (this value is characterized by a return period longer than 100 year), and wide urban and rural areas were flooded, especially downstream of Padova. Damage was extensive and so this event is used as a reference event in the design of hydraulic structures.

The aim of the present work is to analyse the hydraulic risk of the area between Padova and the lagoon of Venice in a flood situation similar to the one in 1966 using the numerical model described above.

In particular, a partial reduction of the flood risk could be achieved using the waterway PD-VE to convey part of Brenta River discharges into the Lagoon of Venice. Waterway PD-VE consists in a channel of trapezoidal shape (about $5 \mathrm{~m}$-deep and $24 \mathrm{~m}$-wide at the bottom) connecting Padova to the Venice Lagoon and crossing the Brenta River downstream of Padova (Fig. 4). Up to now only the ends of the waterway (from Padova to the right bank of Brenta River and from the Novissimo channel and Venice Lagoon) are completed while the middle part of the waterway (about $10 \mathrm{~km}$ between left bank of the Brenta and the Novissimo channel) and some main regulation structures are still not completed. Also under debate is the possibility of revising the waterway project adjusting the channel shape by widening the bottom width from $24 \mathrm{~m}$ to $32 \mathrm{~m}$ to allow the navigation of modern fluvial boats.

From this perspective, it has been verified that the waterway would have no problems to convey discharges up to $350-400 \mathrm{~m}^{3} / \mathrm{s}$; at the same time, high velocities in the waterway can maintain the suspended sediments in the water.

In an integrated framework, it is important to evaluate all the possible consequences of this action. In particular, the influence zone of the fresh water and sediment input should be carefully assessed as well as the maximum velocities induced in the lagoon, to avoid any unhealthy stress for the lagoon environment.

The waterway flows into a lagoon area formed by Brenta alluvions. Historical maps show that this area was characterized by widespread fresh water inputs from the land and a typical tidal landscape with alternation of channels, salt marshes and plains. Nowadays this landscape has been seriously compromised: wide areas of salt marsh are destroyed and channels are silted up. Some of the events in the last century most responsible for degradation are:

- fresh water sources were progressively reduced and stopped causing important variations in the water salinity and in the wetland vegetation, mainly consisting in the disappearance of estuary plants and in the reduction of soil production;

- the environmental deterioration was enhanced by a strong reduction of the tidal circulation due the construction in the $60 \mathrm{~s}$ of a big artificial island designed as the third industrial area of Venice;

- extraction of waters from deep groundwaters (from 1950 to 1970) has generated a subsidence that has been estimated in $\sim 12 \mathrm{~cm}$ while the sea level has risen to about $11 \mathrm{~cm}$ : the relative see rise in the Venice lagoon is then about $23 \mathrm{~cm}$.

Local authorities have planned the reactivation of tidal circulation by dredging works and morphology reconstruction by salt marshes even if difficulties in sediment supply (millions of $\mathrm{m}^{3}$ have been lost in the last century) are delaying the start.

In this context, it is reasonable to assert that a source of sediments and fresh waters is absolutely necessary and useful. Of course, injectioning high volumes of fresh water requires accurate studies on the dispersion, involving 3D calculations not performed yet.

In contrast, the possible source of sediment for the Venice Lagoon, the Brenta river, is reported as an example of rivers in which the human activities have caused severe degradation mainly due to the regulation dams in the mountain basin and the excavations of gravel, directly from the river, downstream to the mountain basin, i.e. south of Bassano.

This loss of gravel sediment, estimated in more than $40 \cdot 10^{6} \mathrm{~m}^{3}$ (Autorità di Bacino, 1997) has caused morphological degradation which is stopping the natural evolution processes in the medium course (braiding and meandering) 


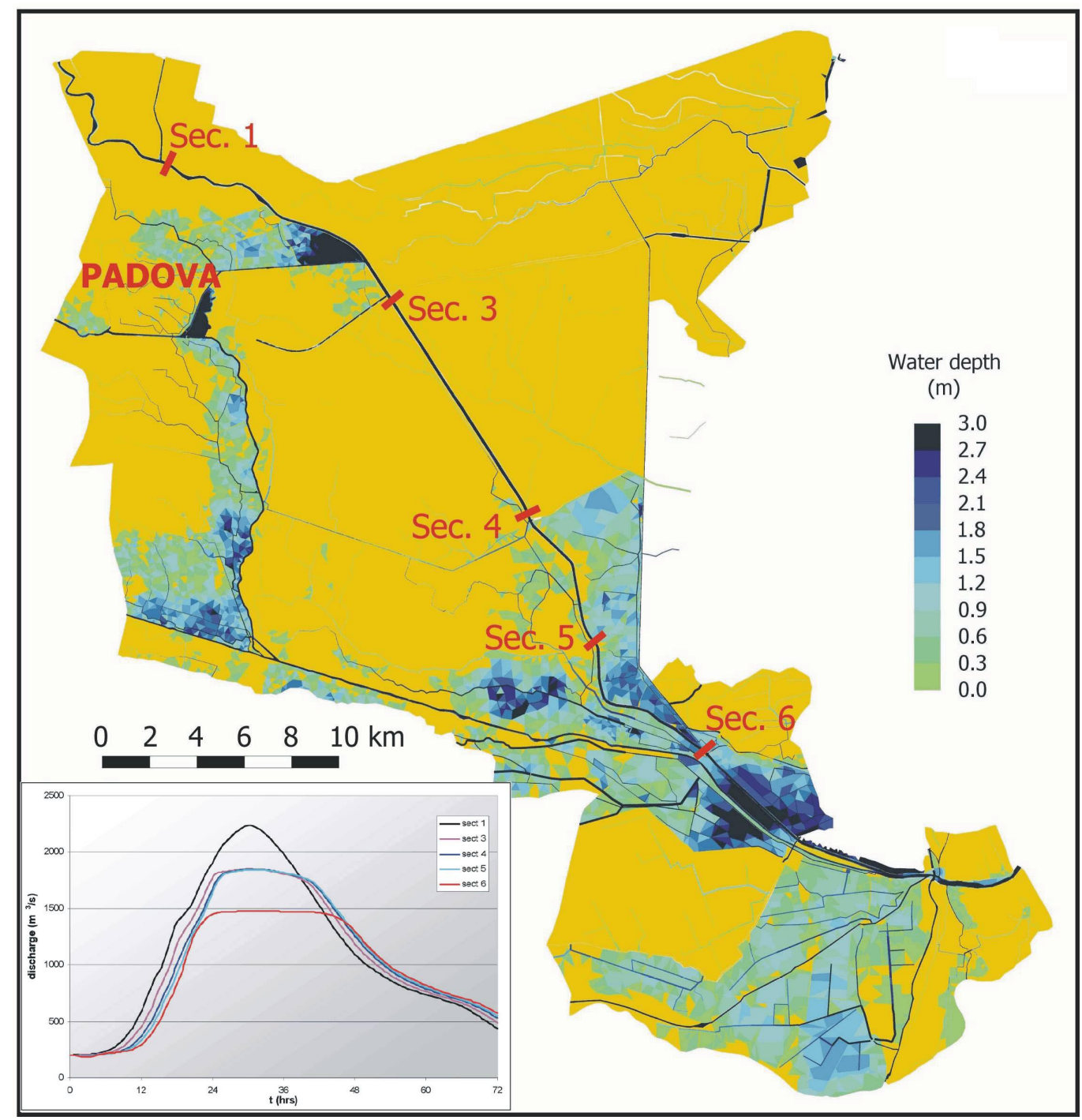

Fig. 5. Maximum calculated flooding depth caused by Brenta-Bacchiglione (1966 event in the actual configuration). Yellow areas represent dry land.

and promoting the deepening of the bed bottom, also in the lower course.

As a sediment supply from Brenta to the Venice Lagoon becomes a sediment loss for the downstream course, in the existing situation, the possibility of a continuous supply of Brenta sediments to the Venice Lagoon needs to be carefully evaluated and, of course, designed in a framework where the whole Brenta basin is taken into account.

The situation here analysed is mainly focused on the management of extreme flooding, i.e. in a situation where the river carries a strong quantities of suspended sediments provided both from previous deposition and from the mountain basin (for instance, from the bottom outlet of the mountain reservoirs). In this context, it seems reasonable to evaluate the validity of the suggested diversion on a local scale framework, looking mainly at the safeguard of residents and their properties and at the absence of disadvantages to the Venice Lagoon.
Of course, the possibility of a continuous supply of sediments from rivers to the Venice Lagoon (Brenta in the central lagoon and Piave in the northern lagoon) is debated in the scientific community. The problem is fashionable but, realistically, it cannot be objectively analysed unless all the aspects of the sediment source are clearly defined and until the possible disadvantages of the sediment and fresh water supply are clearly identified, i.e. the physical and chemical properties of daily fresh waters and sediments. In other words, the actual chemical composition of water and sediments in the low course (south of Padova) could not allow the discharge in the Venice Lagoon.

In the examination of the results and in the conclusions, a few remarks are made. Some of these contributions are probably not new to the scientific debate but they can lead to new reflections, introducing the reader to a real problem in the northeast of Italy. 


\section{Simulations}

The situation of Brenta River and its main tributary in the plain (Bacchiglione) was investigated with the 2D-1D depth integrated model described in the previous chapter. A region of $3000 \mathrm{~km}^{2}$ close to the main rivers has been discretized with a 2D-1D mesh (made of more than 200000 triangular elements and about 10000 1D channels), modelling a distance of $\sim 100 \mathrm{~km}$ in the Brenta River and $\sim 60 \mathrm{~km}$ in the Bacchiglione River (Fig. 4). Bacchiglione River joins the Brenta River $\sim 6 \mathrm{~km}$ away from the sea, creating a single estuary. The $2 \mathrm{D}$ computational domain is merged with a $1 \mathrm{D}$ network to represent the role of both the small channels and the regulation devices like weirs, sluice, banks, water pumps, one-way valves, pipes, etc. ...

Three simulations have been carried out with no changes on the applied boundary conditions, which are always those estimated for the 1966 event, i.e. discharges imposed at the upstream part of the rivers and water level values imposed at the estuary. Several internal conditions are imposed in the inner domain to represent all the regulation devices. The Bacchiglione and Brenta rivers are separated from the country by banks both on the left and in the right side.

Focusing here on the two main rivers, the Brenta River is characterized by an imposed maximum discharge of $\sim 2800 \mathrm{~m}^{3} / \mathrm{s}$ at the closure of the mountain basin in Bassano del Grappa, reducing to $\sim 2100 \mathrm{~m}^{3} / \mathrm{s}$ at Limena. The Bacchiglione River at the entrance of the computational domain has an imposed maximum discharge of $800 \mathrm{~m}^{3} / \mathrm{s}$. The downstream boundary condition consists of a semidiurnal tidal force characterized by an excursion from $0.75 \mathrm{~m}$ m.s.l. to $1.75 \mathrm{~m}$ m.s.l. Other conditions have been analysed in a different study (Carniello, 2000) as well as the influence distance of the downstream boundary condition. It is sufficient to say that the tidal effect vanishes after less that $5 \mathrm{~km}$.

No discharges were considered flowing from Bacchiglione to Brenta rivers by the way of Piovego. Finally, a simulation involving morphological modelling was performed to make preliminary verifications on the effect of the diversion of discharges and sediment into the Lagoon of Venice. In this case the $2 \mathrm{D}$ sediment transport module has been coupled with the 2D hydrodynamic one.

In order to save computational resources, the computational domain has been divided into two subdomains, separating the hydraulic problems of the Brenta River from those of the Venice Lagoon.

In the following paragraphs results of these simulation are discussed. In the calculation we assume that bank overflows never generate a bank collapse, although such failure usually occurs.

\subsection{First simulation: actual configuration}

The actual situation does not differ very much from that in 1966 (Fig. 5) although something has changed after the catastrophic event. The main change is that the northern suburbs of Padova and lots of urban areas in the country are flooded: the northern areas of the city of Padova between Brenta and Piovego are submerged by more than $2 \mathrm{~m}$ of water. Damage caused by the alluvium is probably very important as in that area there are small towns and prosperous industrial plants.

During the event of 1966 a failure on the right bank of Piovego (the right bank was at a lower elevation than the left one) saved Padova and its suburbs from the waters, flooding the areas situated on right side of the bank. It's remarkable to report here that the sluice gate, designed by Paleocapa at the outlet of Piovego channel into the Brenta River, was never realized.

In the reconstruction after 1966 event, the right bank was restored to an elevation higher than the left one and currently the areas on the left side are characterised by high flood risk while in 1966 the same areas were not flooded: these considerations show some of the inadequacies of using common practises based on locating the areas exposed to flood hazard by just looking at the historical alluvium. Nevertheless, this methodology is necessary but not sufficient, especially when historical records are not available: a modelling tool can provide useful help in acquiring information on flood hazard and in the design of safeguards.

The analysis on the river banks has lead to findings that indicate the Piovego banks are characterized by a top elevation lower than those of the Brenta River. During the flood the Brenta River water overflows over the Piovego banks and the maximum discharge reduces from $\sim 2200 \mathrm{~m}^{3} / \mathrm{s}$ to $\sim 1800 \mathrm{~m}^{3} / \mathrm{s}$, preserving the middle course from inundation with very limited safeguard gap $(<50 \mathrm{~cm})$.

The situation in the low course of Brenta River is as dangerous as in the upstream part. As it happened in the 1966, wide areas are flooded by the water from Sect. 5 to Sect. 6 (Fig. 5). Several old studies asserted that the maximum discharge conveyed by the low course of Brenta was $\sim 1500 \mathrm{~m}^{3} / \mathrm{s}$.

The hydraulic situation of the Bacchiglione River cannot be neglected and it is probably as dangerous as the one that of the Brenta River. River banks cannot contain the maximum discharge and inundation involves the whole western areas even if the water overflows over the banks in a limited number of locations. The small channel network and the sloped ground act in propagating the inundation in the southern direction down to Bovolenta (Fig. 4) where flooding waters are stopped by the left bank of the Cagnola channel (active with a maximum imposed discharge of $\sim 90 \mathrm{~m}^{3} / \mathrm{s}$ ). Maximum discharge in the Bacchiglione River upstream of Padova is $\sim 800 \mathrm{~m}^{3} / \mathrm{s}$ and it decreases to $\sim 700 \mathrm{~m}^{3} / \mathrm{s}$ downstream of Padova at the beginning of the north-south course. The diffused bank failing along the middle course reduces the maximum discharge to $\sim 550 \mathrm{~m}^{3} / \mathrm{s}$ upstream of Bovolenta and then to $400 \mathrm{~m}^{3} / \mathrm{s}$ at the confluence in Brenta River.

It is necessary to point out that the inundations are related only to the main rivers (the Bacchiglione and Brenta) as we assume that the country between the Brenta and Bacchiglione do not contribute with effective rainfall; this unrealistic assumption permits us to separate the problems (and 


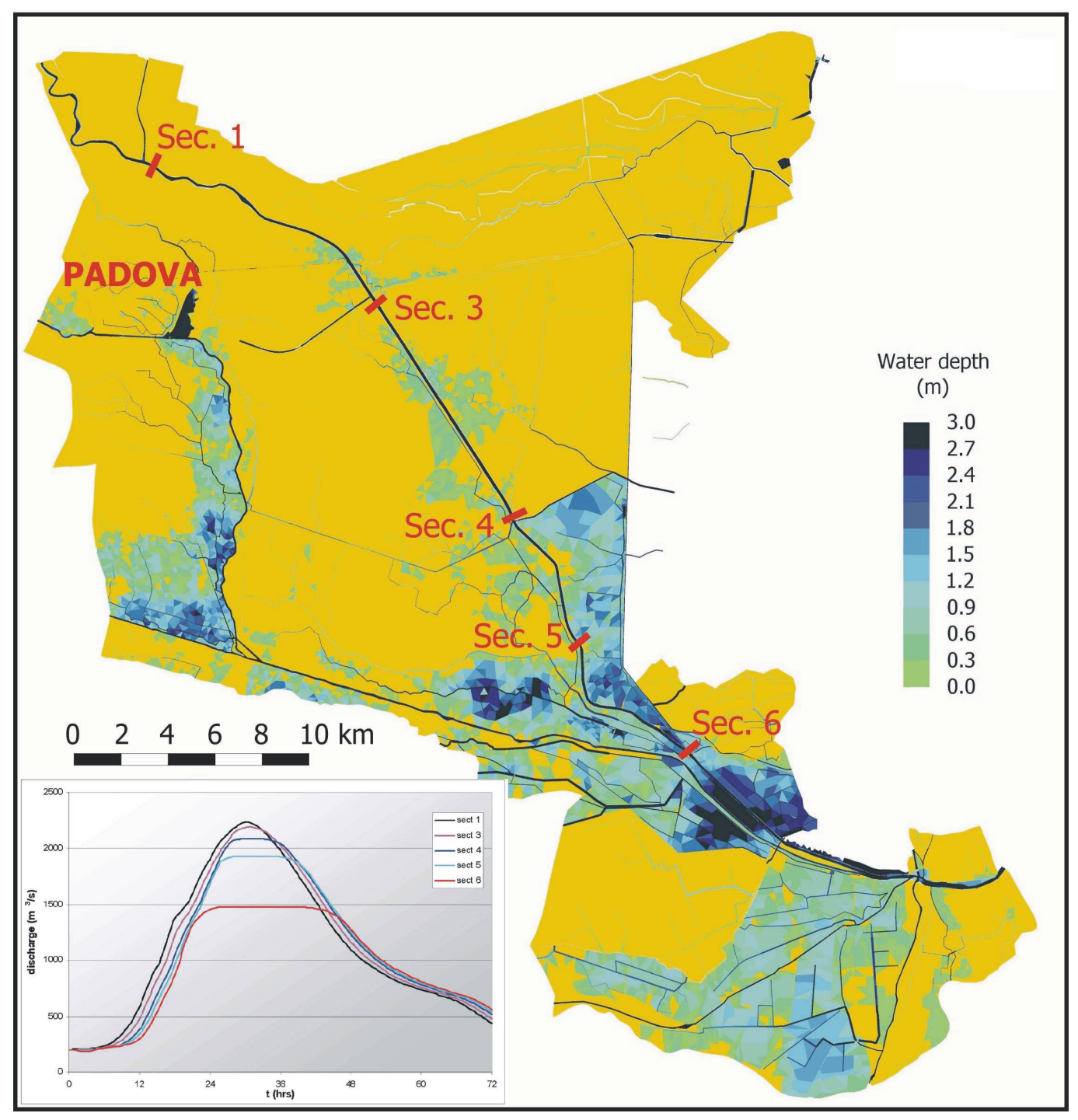

Fig. 6. Maximum calculated flooding depth caused by the 1966 Brenta-Bacchiglione event in a configuration where Piovego banks are raised. Yellow areas represent dry land.

the possible damage and safeguard solutions) induced by the main rivers from those generated by the secondary channels.

\subsection{Second simulation: the raising of the Piovego banks}

The first safeguard solution has lead to the first restoration work: the Piovego banks are increased to an elevation that further surmounting impossible. The same effects would be attained by the construction of the hydraulic structure at the outlet as designed by Paleocapa.

Unfortunately this is not the real solution of the problem as inundations are simply translated downstream because of the higher discharges flowing. No other mitigation interventions are planned at this stage.

As shown in Fig. 6, the bank raising preserves Padova suburbs from inundation and almost the whole discharge can flow downstream; the increasing discharge flowing downstream causes a general increment of water levels in the mid- dle course: for instance, at the intersection between the Piovego waterway and the Brenta River the water level rise is found to be higher than $70 \mathrm{~cm}$, that is sufficient to generate the surmounting of the right banks of the Brenta in the north. The flooding volume is not similar to the first case analysed but a question arises at this point: "what would it happen if the bank breaks?".

In other words, the above intervention cannot save Padova from risk hazard, as the consequences of a break in the bank would be catastrophic. The model proposed can simulate a break failure. It would be interesting to analyse the problem in details but this falls beyond the scopes of this paper.

The land in the middle course is definitely in a worse situation than before as the river surmounts its banks in several places. The situation is still worse since the safety gap in the water level is less than $20-30 \mathrm{~cm}$ throughout the banks that are not surmounted. 


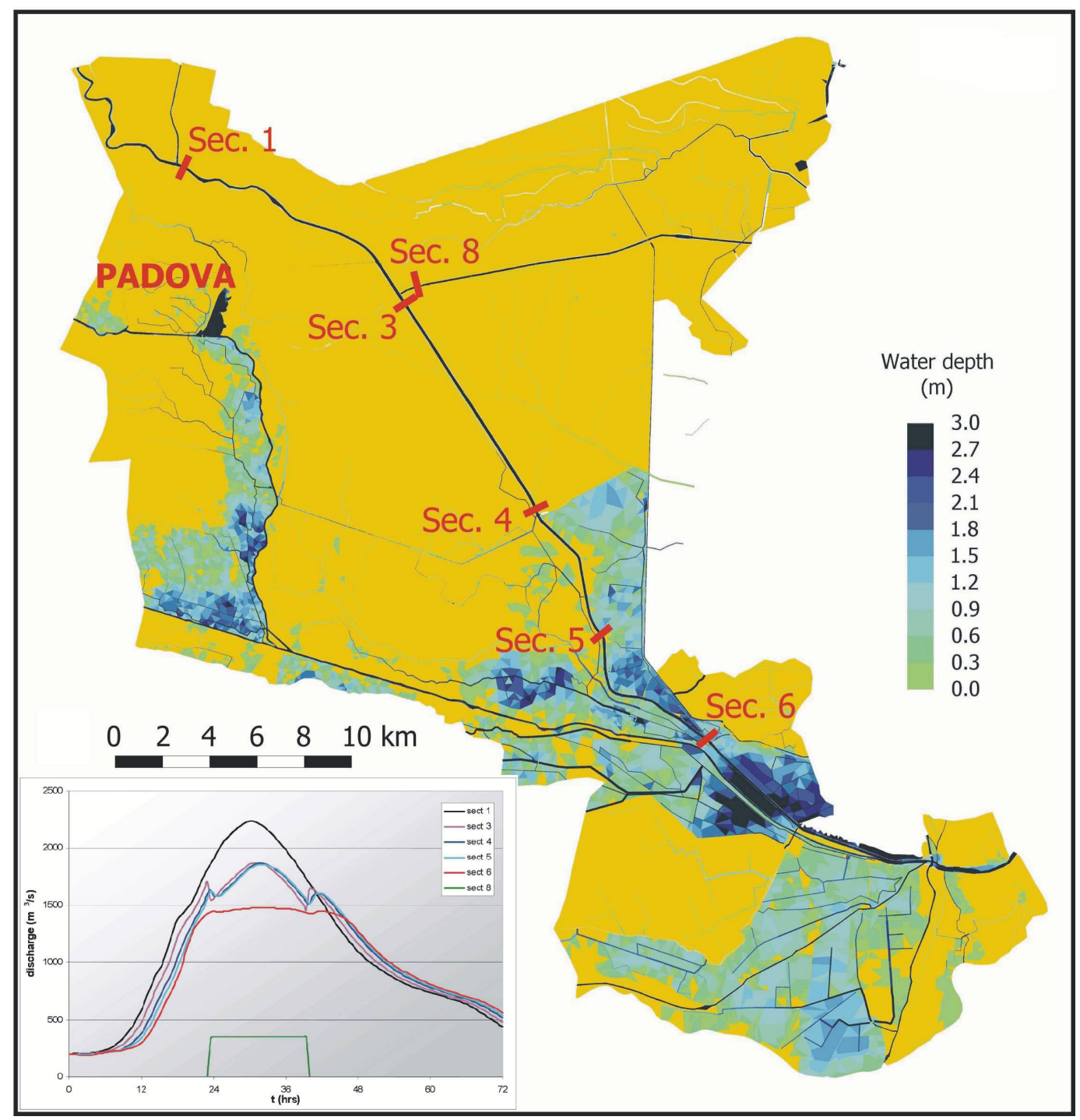

Fig. 7. Maximum calculated flooding depth caused by 1996 Brenta-Bacchiglione event in a configuration where Piovego banks are raised and the waterway has diverted $350 \mathrm{~m}^{3} / \mathrm{s}$ in the Venice Lagoon. Yellow areas represent dry land.

Once again the maximum discharge entering the low course is $\sim 1500 \mathrm{~m}^{3} / \mathrm{s}$ and the areas inundated by the Bacchiglione River are the same as described in the previous case: no changes in the geometry or in the boundary condition had been made.

The results show clearly that the effectiveness of the proposed solution is negligible in a global management objective. The right design should encompass either a reduction on the flood discharges or the whole restoration of the banks in the middle and lower course.

\subsection{Third simulation: diversion of part of Brenta discharges into the Venice Lagoon}

The previous simulations have shown that the maximum discharge that the Brenta River can convey safely south of Padova is approximately $1800 \mathrm{~m}^{3} / \mathrm{s}$, while in the lower course the discharge capacity decreases to $1500 \mathrm{~m}^{3} / \mathrm{s}$.
Even though the following safeguard solution has been discussed a lot in the local context since 1990 there is not a unified opinion concerning this problem. This solution would consists in a diversion of part of the Brenta River's discharge into the Venice Lagoon by the completion of the waterway PD-VE. Furthermore, the left bank of Piovego has been raised up to the Brenta one because a lower bank elevation would represent a weakness in the whole flood defence project.

In Fig. 7 the maximum depths are represented in the situation obtained by a diversion of $350 \mathrm{~m}^{3} / \mathrm{s}$ in the lagoon during the peak discharge phase. We set a linear increment of the derived discharge from 0 to $350 \mathrm{~m}^{3} / \mathrm{s}$ in $1 / 2 \mathrm{~h}$, a constant value of $350 \mathrm{~m}^{3} / \mathrm{s}$ has been maintained for $14 \mathrm{~h}$ and then the derived discharge comes back to a null value in $1 / 2 \mathrm{~h}$. 


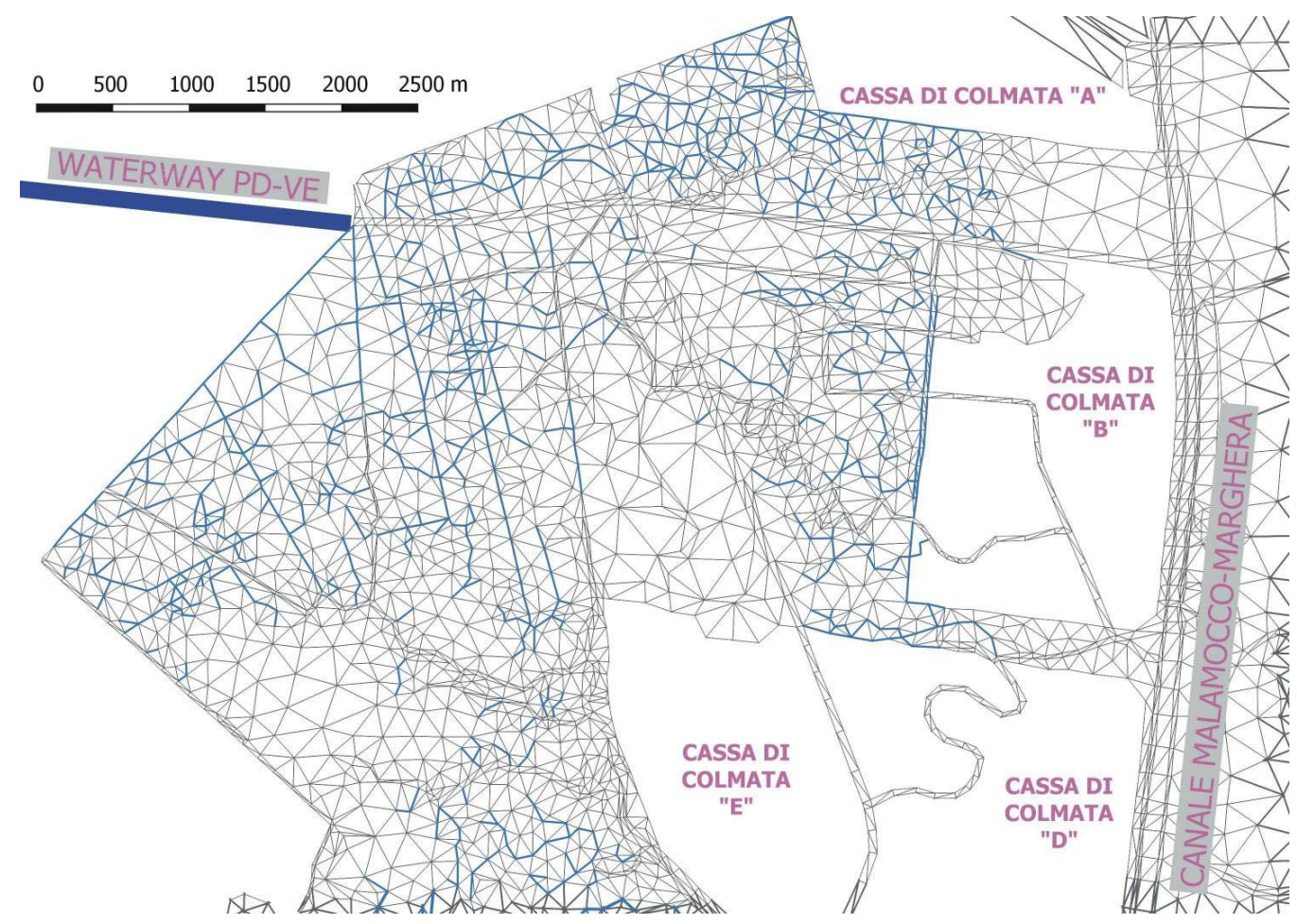

Fig. 8. Enlargement of the 2D-1D mesh of the lagoon region where the waterway PD-VE flows into. A joining channel (Canale Cunetta) connects the waterway outlet to the Canale Malamocco-Marghera.

The results show the inundation is completely absent in the whole middle course. Padova and its suburbs are preserved from damage resulting from both the Piovego waterway and the Brenta River. In this case the safeguard gap assumes a value $\geq 50 \mathrm{~cm}$ approximately up to Sect. 4 .

A local deficiency is still present at Sect. 4 (it takes place along a short length and can be easily resolved by local restoration) and downstream of Sect. 5, where the hydraulic situation has remained relatively unchanged.

\subsection{Fourth simulation: effects in the Venice lagoon}

The total water volume diverted in $15 \mathrm{~h}$ (Fig. 7) from Brenta River to the Venice Lagoon is about $20 \times 10^{6} \mathrm{~m}^{3}$ that would produce a uniformly distributed increment of the water level lower than $5 \mathrm{~cm}$ in the whole lagoon. This increment can be acceptable also in the case where all three inlets will be timely closed to prevent Venice from flooding by extraordinary high tides.

We characterize the Brenta River, downstream of Padova, with a non cohesive soil $\left(\mathrm{d}_{50}=100 \mu \mathrm{m}, \mathrm{d}_{90}=2 \mathrm{~mm}\right.$ and the relative density $\rho_{s} / \rho_{w}=2$ ). These value seem reasonable as the sediment composition of Brenta at Piazzola sul Brenta, $10 \mathrm{~km}$ northern from Limena, is found to be $\mathrm{d}_{50}=400 \mu \mathrm{m}$ and $d_{90}=10 \mathrm{~mm}$ (Autorità di Bacino, 1997). We assumed that in the Brenta river, upstream the waterway diversion, the suspended sediment concentration is in an equilibrium state with the local flow. It seems a reasonable hypothesis as the Brenta river downstream Padova maintains an almost con- stant shape confined by banks on both the right and the left side.

Having set the current depth equal to $10 \mathrm{~m}$ and the flow velocity during the centenary flood equal to $2.5 \mathrm{~m} / \mathrm{s}$ (as calculated in the third simulation), the bottom volumetric concentration would be $\mathrm{C}_{\text {bottom }}=\sim 15 \%$ (Van Rijn, 1984b). Having set the reference height for the concentration $\mathrm{a}=1 \mathrm{~m}$, i.e. $\mathrm{a} / \mathrm{D}=0.1$, the depth average concentration (Van Rijn, 1984b) is almost equal to $1 \%$. This value seems comparable to an average concentration equal to $0.1 \%$ during a $1000 \mathrm{~m}^{3} / \mathrm{s}$ flood (Autorità di Bacino, 1997).

In the computation of the dispersion of the new sediment supply in the Venice lagoon, we have assumed a volumetric sediment concentration at the waterway outlet in the Venice Lagoon equal to $0.5 \%$, to take into account a possible lower effective concentration of the diverted waters. In this case, the total amount of sediment discharged into the lagoon reaches $1 \times 10^{5} \mathrm{~m}^{3}$ during the centenary flood. The sediment load could be derived at a variable distance from the bottom of the river, in this way ensuring a flexibility in the management of the sediment intake and in the size composition.

The simulation has been performed on a very refined 2D computational domain, reproducing only the Venice Lagoon. Figure 8 shows an enlargement of the lagoon area where waterway flows into.

The area reached by the sediments extends around the main channel (a "connecting" channel, Fig. 8) connecting the waterway to the "live" lagoon. In this channel, the velocity 

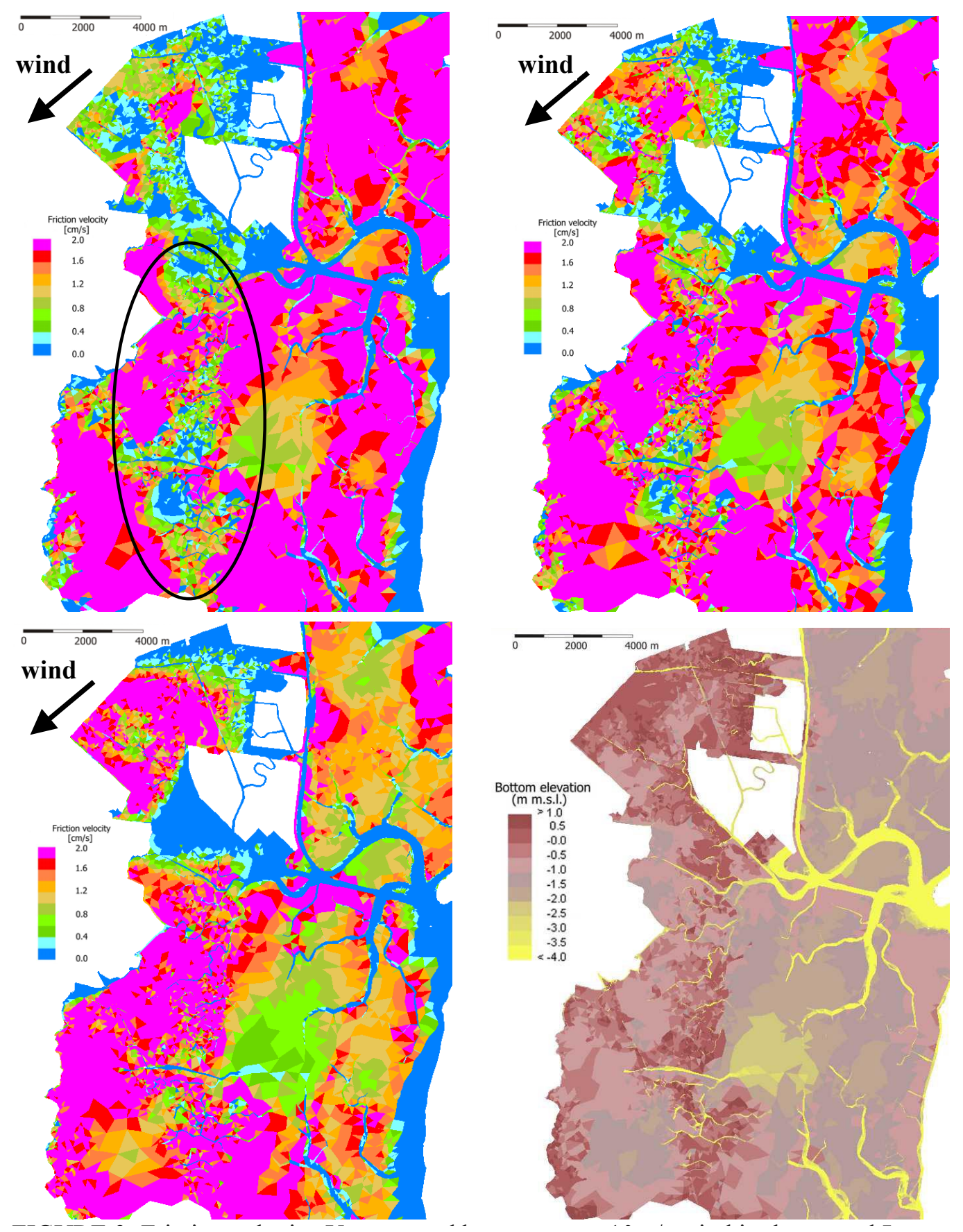

Fig. 9. Friction velocity $U_{f}$ generated by a constant $10 \mathrm{~m} / \mathrm{s}$ wind in the central Lagoon on a constant sea level (top left: $+0.30 \mathrm{~m}$, top right: $+0.50 \mathrm{~m}$ and bottom left: $+0.80 \mathrm{~m}$ m.s.l.). The bathymetry is shown in the bottom right panel. In the top left picture, the areas of the southern central lagoon where the sediment supply is mostly required are indicated.

induced by the waterway does not exceed $1 \mathrm{~m} / \mathrm{s}$. A preliminary simulation with a lower sediment diameter, $\mathrm{d}_{50}=20 \mu \mathrm{m}$ (a very fine silty sand), showed that the fine sediments can spread over the whole area represented in Fig. 8.

In the connecting channel, the calculation shows the sediment deposition is almost $1 \mathrm{~m}$ on the western side near the waterway and almost null in its middle length. The sediment settling in secondary channels, shoals and marshes seems limited to the areas closest the connecting channel where it can be slowly re-suspended and transported in the lagoon by the action of currents and waves. In contrast, a dredging-boat can restore safe conditions for navigation in the main channel: the dredged sediments can be deposited over existing marshes areas that need a sediment supply or in other areas where they can get mobilized by waves, promoting a mechanism of salt-marshes reconstruction. 
With respect to these depositing areas, it is worthwhile evaluating, even if only with a preliminary approach, the efficacy of waves to resuspend the sediments and the capability of tidal currents to transport them also in the southern central lagoon. In this part of the lagoon, wide areas of salt marshes have disappeared and many others are still disappearing: therefore, there is an urgent necessity to provide in this areas new sediments and to promote a restoration mechanism.

It seems clear that the new supply of sediment would not nullify the causes of the morphological degradation. The sediment supply to the lagoon is a single (reasonable) intervention that finds its validity only within other interventions aiming at a) the reduction of the sediment loss at the armoured inlets, b) the reduction of the resuspension capacity of waves and c) the reduction of the current energy in the central lagoon.

Figure 9 shows the results of a new numerical model (Carniello, private communication, 2004) that solves the conservation of Wave Action (Whitham, 1974) in a monochromatic form, neglecting the wave-current interaction and the bottom refraction effects:

$$
\frac{\partial N}{\partial t}+\frac{\partial}{\partial x} c_{g x} N+\frac{\partial}{\partial y} c_{g} y N=\frac{S}{\sigma}
$$

where $N$ is the wave action, $\boldsymbol{c}_{g}=\left(c_{g x}, c_{g y}\right)$ the group velocity, $\sigma$ the frequency and $S$ the source term taking into account for wind, bottom friction, breaking and white-capping.

Having characterized the Venice Lagoon with $\mathrm{d}_{50}=100 \mu \mathrm{m}, \mathrm{d}_{90}=200 \mu \mathrm{m}$ and $\rho_{s} / \rho_{w}=2.0$, the critical friction velocity is $\sim 0.01 \mathrm{~m} / \mathrm{s}$. The bed shear stress $U_{f}$ generated by the orbital velocity near the bottom, $U_{\text {bottom }}$ ( $\mathrm{T}=2 \mathrm{~s}$ in agreement with the available measurements) is evaluated as (Fredsoe, 1992):

$U_{\text {bottom }}=\frac{\pi H}{T \sin h(k D)} \quad U_{f}+\sqrt{\frac{f}{2}} U_{\text {bottom }}$

where $H$ is the wave height, $k$ the wave number, $D$ the water depth and $f$ is the friction factor assumed equal to 0.01 .

Figure 9 refers to a situation where a $10 \mathrm{~m} / \mathrm{s}$ wind blowing from north-east direction ("BORA") generates a wave field that grows with the available fetch and dissipates its energy due to the interaction with the bottom, due to the breaking and due to the white-capping. The friction velocity $U_{f}$ assumes values that are almost twice the critical friction velocity in wide areas west of Casse di Colmata. The resuspension capacity of waves is varies greatly during the reference tide considered $\left(\mathrm{T}=12 \mathrm{~h} \mathrm{~h}_{\text {sea }}=-0.2 /+0.8 \mathrm{~m}\right.$ m.s.l., i.e. a normal spring tide). At low tidal levels, marshes and shoals act both limiting the available fetch and dissipating the wave energy; at higher levels the salt marshes get submerged and the fetch grows sizeably, allowing for the formation of resuspending waves.

For the wind considered the shallow areas closest to the joining channel seem only marginally involved in resuspension. Better results are obtained for a different wind direction
$(10 \mathrm{~m} / \mathrm{s}$ "SCIROCCO" wind from south-south east) allowing conditions for the complete resuspention in the whole areas around the connecting channel.

These results, even if they require further analysis and verifications, seem to indicate that the settled sediments provided from waterway in shoals and marshes can get resuspended by the waves. By contrast, it is reasonable to assess that just a small amount of the sediment supply from the Brenta diversion can reach the southern part of the central lagoon as the main channels do not have the capacity to transport them due the low tidal velocities, causing the channel filling by the settlement of suspended sediments.

Figure 10 shows the contour of suspended sediment concentration in a situation where a $10 \mathrm{~m} / \mathrm{s}$ wind blows from north-east direction and a spring tide $(\mathrm{T}=12 \mathrm{~h}$ and $\mathrm{h}_{\text {sea }}=-0.2 /+0.8 \mathrm{~m}$ m.s.l.) is forcing the system. The situation obtained with a $10 \mathrm{~m} / \mathrm{s}$ wind blowing the from southsouth east direction doesn't lead to a very different conclusion even if the resuspention in the areas located southwestern the Cassa di Colmata " $E$ " is more important. It is worthwhile noticing that the suspended sediment concentration in the channels is much lower than in the shallows. The cause is found in Fig. 9 that clearly indicates that the resuspension capacity of waves acts mainly in the shallow waters.

A sediment loss at the inlets of about $10000 \mathrm{~m}^{3}$ in a $12 \mathrm{~h}$ tidal cycle has been calculated when a north-east wind blows at $10 \mathrm{~m} / \mathrm{s}$. This value is about 4 times bigger than the one calculated (Martini et al., 2003) in the absence of resuspension and makes sense of the value of $1000000 \mathrm{~m}^{3} /$ year that is commonly accepted in the scientific debate.

\section{Conclusions}

We have demonstrated the hydraulic risk of the plain of Brenta River basin, analysing the flood propagation in the rivers and on the countryside when river banks do not contain the discharges anymore.

The proposed 2D-1D hydrodynamic model has been applied successfully in studying the Brenta River and the Venice Lagoon. The numerical model couples a realistic description of the channel network by the insertion of all the regulation devices with an accurate resolution of the flow field. Considering that a 3 day simulation takes a couple of hours using a modern processor, the usage of the tool is strongly enhanced.

The 2D morphological model has revealed its robustness in dealing with very complicated geometry. As the coupling 2D-1D is not active yet in the sediment transport module, the obtained results are to be considered as preliminary results because the small channels play a fundamental role in a tidal environment both in hydrodynamics and in dispersion processes.

We have shown the effects obtained by the diversion Brenta River discharges in the Venice Lagoon, producing enhanced conditions not only to the countryside along the Brenta River but also to the lagoon itself. The diversion 

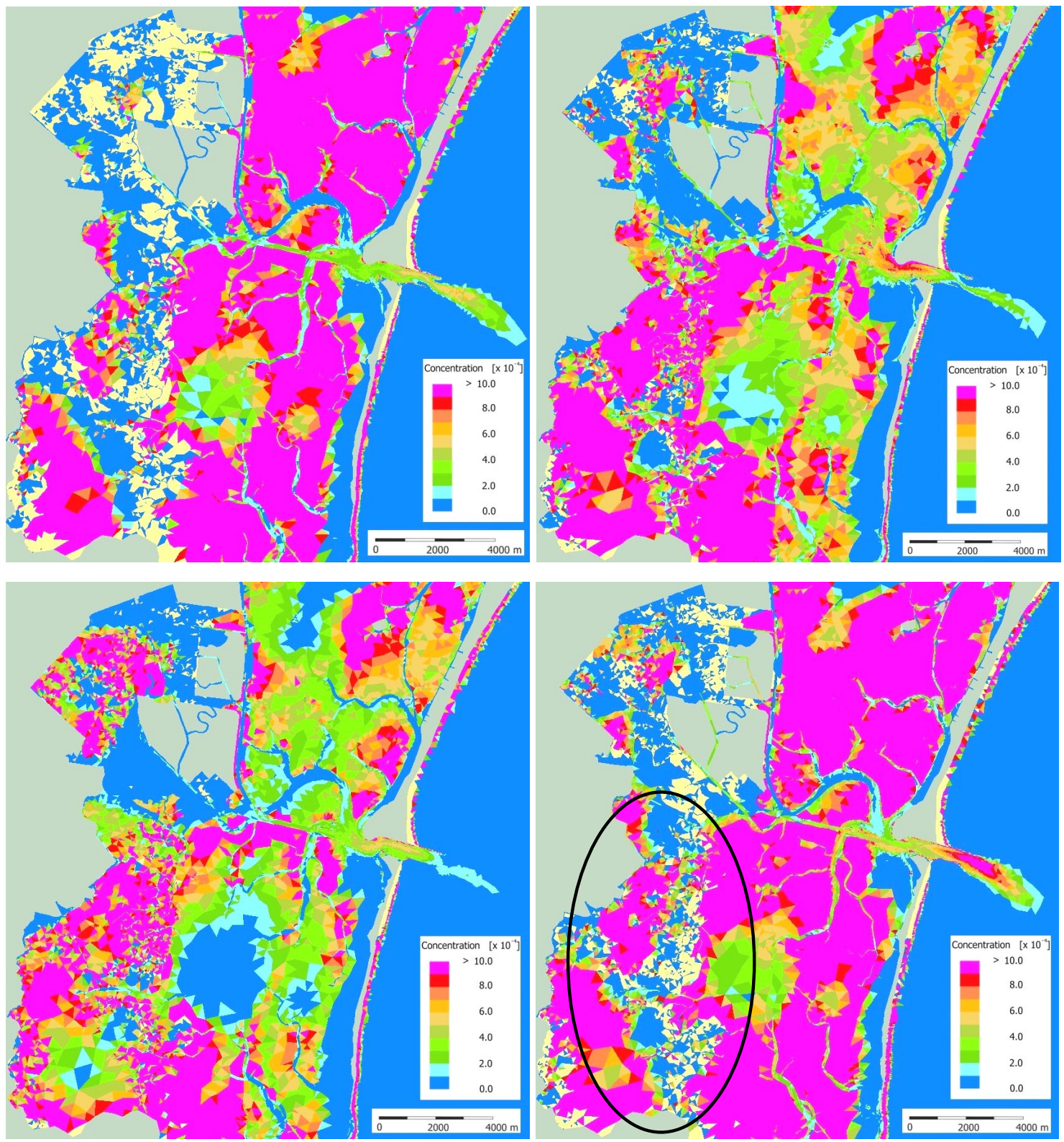

Fig. 10. Contour of suspended sediment concentration due to the action of wind-waves (generated by a $10 \mathrm{~m} / \mathrm{s}$ wind from a north east direction) and tidal currents $\left(\mathrm{T}=12 \mathrm{~h}\right.$ and $\mathrm{h}_{\mathrm{sea}}=-0.2 /+0.8 \mathrm{~m}$ m.s.1.): $\mathrm{t}=0$ (top left), $\mathrm{t}=1 / 4 \mathrm{~T}$ (top right), $\mathrm{t}=1 / 2 \mathrm{~T}$ (bottom left) and $\mathrm{t}=3 / 4 \mathrm{~T}$ (bottom right). The areas of the southern central lagoon where the sediment supply is mostly required are indicated in the bottom right picture. Light colour areas represent dry land.

of the Brenta River discharges can alleviate the hydraulic deficiency in the whole middle and low course, preserving Padova and the countryside from inundation. Waterway diversion reduces the discharges flowing downstream of Padova, where the banks are not suitable to convey the maximum discharges (return period of 100 years).

It is important to point out that a significant reduction of the maximum discharge of the Brenta River can be obtained in the mountain basin by storing the peak discharges into hydropower reservoirs. The possibility has been recently investigated (Rinaldo et al, 2003) and the operative terms in the reservoir management are still under discussion and development by the local authorities. Both the two regulatory solutions can work very efficiently in a combined way, remembering that some bank restoration in the lower course is still necessary.

The aspects linked to the sediment supply deserve some considerations, starting from the causes of the sediment lack in the whole medium and low course of the Brenta River.

It is worthwhile pointing out that the future management of the mountain reservoirs in the Brenta river basin, specially the Corlo reservoir in the Cismon tributary $\left(630 \mathrm{~km}^{2}\right)$, should 
take into account the utilization of the dam bottom outlets with respect to the release of solid and liquid discharges not only during extreme events but also during normal events.

As the Corlo reservoir $\left(40 \cdot 10^{6} \mathrm{~m}^{3}\right)$ has reduced its volume to about $1 / 2$ in less than 50 years due the interception of the whole sediments from its mountain basin (in the autumn, the reservoir is at a low water level both for flood safeguard and for the summer utilization of the volume: in this way, all the normal floods and the sediment transported are completely stored), it seems reasonable to try to solve the problems of both the mountain reservoirs (the abundance of settled sediment) and the Brenta River (the lack of sediment) in an integrated framework.

The release of sediment from the mountain reservoirs would certainly have a positive effects in contrast to the morphological degradation of the Brenta River in the last century due to the deepening of the bottom in the medium course, varying from 5 to $10 \mathrm{~m}$ in the whole length from Bassano del Grappa $\left(\mathrm{d}_{50} \approx 70 \mathrm{~mm}\right)$ to Limena $\left(\mathrm{d}_{50} \approx 0.4 \mathrm{~mm}\right)$. A deepening of the bottom is found also in the low course ( $\sim 2 \mathrm{~m}$ from Strà to the estuary in the last ten years), while an almost stable bottom level has been maintained from Limena to Strà due the presence of a check dam.

A specifically designed supply of sediment from the mountain basin would increase the bed elevation in the whole medium and low course, making available a continuous supply of suspended sediment also to the Venice Lagoon.

Lastly, as the Brenta river drains the groundwater in the southern part of the medium course (from Fontaniva to the south), a raising of the bottom elevation will reduce the groundwater losses, providing new water resources for irrigation and human needs.

Urgent studies are necessary before concluding the analysis on the lagoon, regarding many important aspects such as a) the effect of a large injection of fresh waters on vegetation and fishes, b) the possibility to distribute sediments in the central Lagoon using some border channel outside the lagoon and c) the efficacy of resuspension of the settled sediments by currents and waves.

This last aspect has been preliminary investigated showing that sediments can be resuspended by wind waves both in the region where the waterway flows into and in the whole central lagoon but considerations about the frequency and the duration of the resuspension processes by wind waves and the solid volumes involved are still missing.

It seems difficult that the sediment supply provided by the waterway PD-VE can reach the southern central lagoon where there is the most important need for marsh restoration. Of course, the sediments can be transported with dredging boats from the waterway inlet to the requiring areas, for instance behind the marshes of the central lagoon where they can get resuspended by the waves (Fig. 9) and then transported by the currents (Fig. 10). In this context, the solution at step b) would be an effective alternative and it deserves special attention by a research group at the Department IMAGE of the University of Padova, headed by L. D'Alpaos.
Acknowledgements. This research has been partially funded by the RIMOF project and Co.Ri.La 2000-2004 research program (Linea 3.7 - Modelli previsionali). L. D'Alpaos's suggestions and ideas are gratefully acknowledged. P. Martini also thanks Studio Altieri S. P. A. and Palomar s.r.l., gratefully remembering V. Altieri for his support. Two anonymous referees are acknowledged for their review.

Edited by: L. Garrote

Reviewed by: two referees

\section{References}

Autorità di bacino dei fiumi Isonzo, Tagliamento, Livenza, Piave, Brenta-Bacchiglione, Studi finalizzati alla redazione del piano di bacino del fiume Brenta-Bacchiglione. Sistemazione fluviale e ricomposizione ambientale del medio Brenta ai fini della moderazione delle piene, a cura di Studio Altieri s.r.l. e Ipros Ingegneria Ambientale s.r.l., 1997.

Bijker, E. C.: Mechanics of sediment transport by the combination of waves and currents, Proc. of the Short Course on Design and Reliability of Coastal Structures, Venice, 1992.

Carniello, L.: Modellazione matematica dei fenomeni di inondazione del territorio posto in adiacenza ai fiumi del sistema idrografico Brenta-Bacchiglione, Honour thesis, Università di Padova Dipartimento IMAGE, 2000.

Casetta, P.: P. Paleocapa, Memoria Idraulica sulla regolazione dei fiumi Brenta e Bacchiglione, 1843, Presidenza del Consiglio dei Ministri, Dipartimento per i servizi tecnici nazionali, Servizio idrografico e mareografico nazionale, Ufficio compartimentale di Venezia, 2002.

Casulli, V.: Numerical Simulation of Shallow Water Flow, Computational Methods in Surface Hydrology, edited by Gambolati, G., Rinaldo, A., Brebbia, C. A., Gray, W. G., and Pinter, G. F., Springer, 1990.

Cessi, R.: Evoluzione storica del problema lagunare, Istituto Veneto di Scienze, Lettere ed Arti, Venezia, 1960.

Defina, A.: Two-dimensional shallow flow equations for partially dry areas, Water Resources Research, Vol. 36, No. 11, 2000.

D'Alpaos, L. and Defina, A.: Venice Lagoon hydrodynamics simulation by coupling 2D and 1D finite element models, Proc. of VIII International Conference on Finite Elements in Fluids New trends and applications, Barcellona 20-24 sett., 917-926, 1993.

D'Alpaos, L. and Defina, A.: Modellazione matematica del comportamento idrodinamico di zone a barena solcate da una rete di canali minori, Istituto Veneto di Scienze, Lettere ed Arti, Venezia, 1995.

D'Alpaos, L. and Martini, P.: The influence of inlet configuration on sediment loss in the Venice Lagoon, Proc. of Flooding and Environmental Challenges for Venice and its Lagoon: State of Knowledge 2003, Cambridge, 2003.

Fredsoe, J. and Deigaard, R.: Mechanics of coastal sediment transport. Advanced Series on Ocean Engineering, Vol. 3, World Scientific, 1992.

Gambolati, G.: Lezioni di Metodi Numerici, Ed. Cortina, Padova, 479-571, 1994.

Martini, P., D'Alpaos, L., and Carniello, L.: Un modello matematico bidimensionale per lo studio dell'idrodinamica e del trasporto di sedimenti nella Laguna di Venezia, second annual 
workshop of Corila Research Program 2000-2004, Venezia, 2003.

Miliani, L.: Le piene dei fiumi veneti ed i provvedimenti di difesa, Le Monnier, 1939.

Rinaldo, A., Bellin, A., Ferri, M., Marani, M., Rigon, R., Fornasiero, A. and Silvestri, S.: Modellazione matematica del bacino idrografico del fiume Brenta (chiuso a Bassano del Grappa), Dipartimento IMAGE dell'Università di Padova e Autorità di bacino dei fiumi Isonzo, Tagliamento, Livenza, Piave, BrentaBacchiglione, Venezia, 2003.

Talmon, A. M.: Laboratory measurements of the direction of sediment transport on transverse alluvial-bed slopes, J. of Hydraulic Research, 33, 4, 1995.
Thetis-InterPave: Idrovia Padova-Venezia, Quali soluzioni possibili, public report 1999.

Tonini, D.: Le piene nel Veneto, Friuli-Venezia Giulia nel novembre 1966, Accademia nazionale dei Lincei, Quaderno n. 112, 1968.

Van Rijn, L.: Sediment transport, Part 1: bed load transport, J. of Hydraulic Engineering, 110, 10, 1984a.

Van Rijn, L.: Sediment transport, Part 2: suspended load transport, J. of Hydraulic Engineering, 110, 11, 1984b.

Van Rijn, L.: Sediment transport, Part 3: bed forms and alluvional roughness, J. of Hydraulic Engineering, 110, 12, 1984c.

Whitham, G. B.: Linear and Nonlinear Waves, John Wiley, New York, 1974. 